\title{
Rapid progression of an IDH-wild type histological low-grade glioma harbouring TERT promoter mutation and diffuse CD34 expression: a case report
}

\author{
Hongxiang Wang ${ }^{1}$, Cong $\mathrm{Tan}^{2}$, Tao $\mathrm{Xu}^{1}$, Weiqing $\mathrm{Li}^{3}$ \\ ${ }^{1}$ Department of Neurosurgery, Shanghai Changzheng Hospital, Shanghai, China, ${ }^{2}$ Department of Pathology, Cancer Institute of \\ Fudan University, Shanghai, China, ${ }^{3}$ Department of Pathology, Shanghai Changzheng Hospital, Shanghai, China
}

\begin{abstract}
IDH-wild type (WT) histological low-grade gliomas are a rare group with distinct character and prognostic heterogeneity. Studies involving genetic and molecular analyses are warranted to stratify these patients into specific entities for the facilitation of tumour management. In this study, we reported a novel IDH-WT glioma with histological characteristics of a low-grade tumour. Preoperative CT revealed massive calcification of this lesion and MRI showed a mixed hyperintense and hypointense signals on both T1- and T2-weighted images with a slight contrast enhancement. Micrography revealed dense deposits of calcium and diffuse microhaemorrhage in the tumour mass. Immunohistochemical staining showed diffuse expression of CD34 in neoplastic cells but uncertain positivity of glial fibrillary acidic protein (GFAP). Further sequencing found telomerase reverse transcriptase (TERT) promoter mutation in this tumour. Though the patient underwent surgical treatment followed by radiotherapy and temozolomide chemotherapy, the tumour recurred at the eight-month follow-up postoperatively. Taken together, extensive CD34 expression and TERT promoter mutation may empower the potential of malignant transformation to IDH-WT histological low-grade glioma to rapidly progress into glioblastoma.
\end{abstract}

Key words: glioma, pre-GBM, IDH, CD34, TERT.

\section{Introduction}

Adult diffuse gliomas characterized by histological and genetic heterogeneity are refined by 2016 World Health Organization (WHO) classification concerning morphological characterizations and molecular alterations, especially mutations in the IDH1 and IDH2 genes. Thus, IDH mutations stratify both entities of glioblastoma (GBM) and diffuse low-grade glioma with a relatively favour- able prognosis compared to their IDH wild-type (IDH-WT) counterparts [5]. In contrast to the prevalence of wild-type status of IDH in GBM, IDH-WT tumours account for only a small proportion of lowgrade gliomas. However, prognostic heterogeneity still exists in the minority group with varieties in clinicopathological features and imaging characteristics. Investigations in molecular pathogenesis are increasingly needed to understand the essential nature of IDH-WT low-grade gliomas and facilitate

Communicating authors:

Weiqing Li, Department of Pathology, Shanghai Changzheng Hospital, 415 Fengyang Road, Shanghai 200003, China, e-mail: bluehattie@hotmail.com

Hongxiang Wang, Department of Neurosurgery, Shanghai Changzheng Hospital, 415 Fengyang Road, Shanghai 200003, China, e-mail: wanghongxiang27@smmu.edu.cn 
rapid integration into the current clinical classification and management. In this report, we present a novel case with histological characteristics of lowgrade glioma and wild-type status of IDH harbouring diffuse CD34 expression and telomerase reverse transcriptase (TERT) promoter mutation and progressing rapidly.

\section{Case presentation}

Informed consent was obtained from the patient. A 51-year-old woman began with intermittent headache attacks for 12 days and also suffered from short episodes of partial seizures for one week. Historytaking and neurological examination at the time of evaluation revealed no abnormalities. Computed tomography (CT) scans showed a lesion with extensive calcification in the right parietal lobe (Fig. 1A). Unusually, magnetic resonance imaging (MRI) implicated an ill-defined mass accompanied by a cystic change and haemorrhage. Patchy heterogeneous hyperintensity was presented on T1-weighted images with a slight and heterogeneous contrast enhancement, hypointense was seen in round-like areas on both T1- and T2-weighted images, and diffusion-weighted images (DWI) showed highlow mixed signals of this lesion (Fig. 1B-E). Further T2 star-weighted angiography (SWAN) showed hypointensity of the lesion with some curved striplike signals, indicating artery-venous malformation (AVM) with haemorrhage (Fig. 1F). However, cerebral angiography without remarkable findings precluded the diagnosis of AVM. No significant changes of Cho and NAA were detected by magnetic resonance spectroscopy (MRS) (Fig. 1G) as well. Then, the patient underwent surgery. Intraoperative observation demonstrated a massively calcified tumour with a visually indistinct border. Postoperative image study revealed that the lesion was totally resected (Fig. 2A). And the patient was immediately seizure-free, and the headache significantly alleviated.
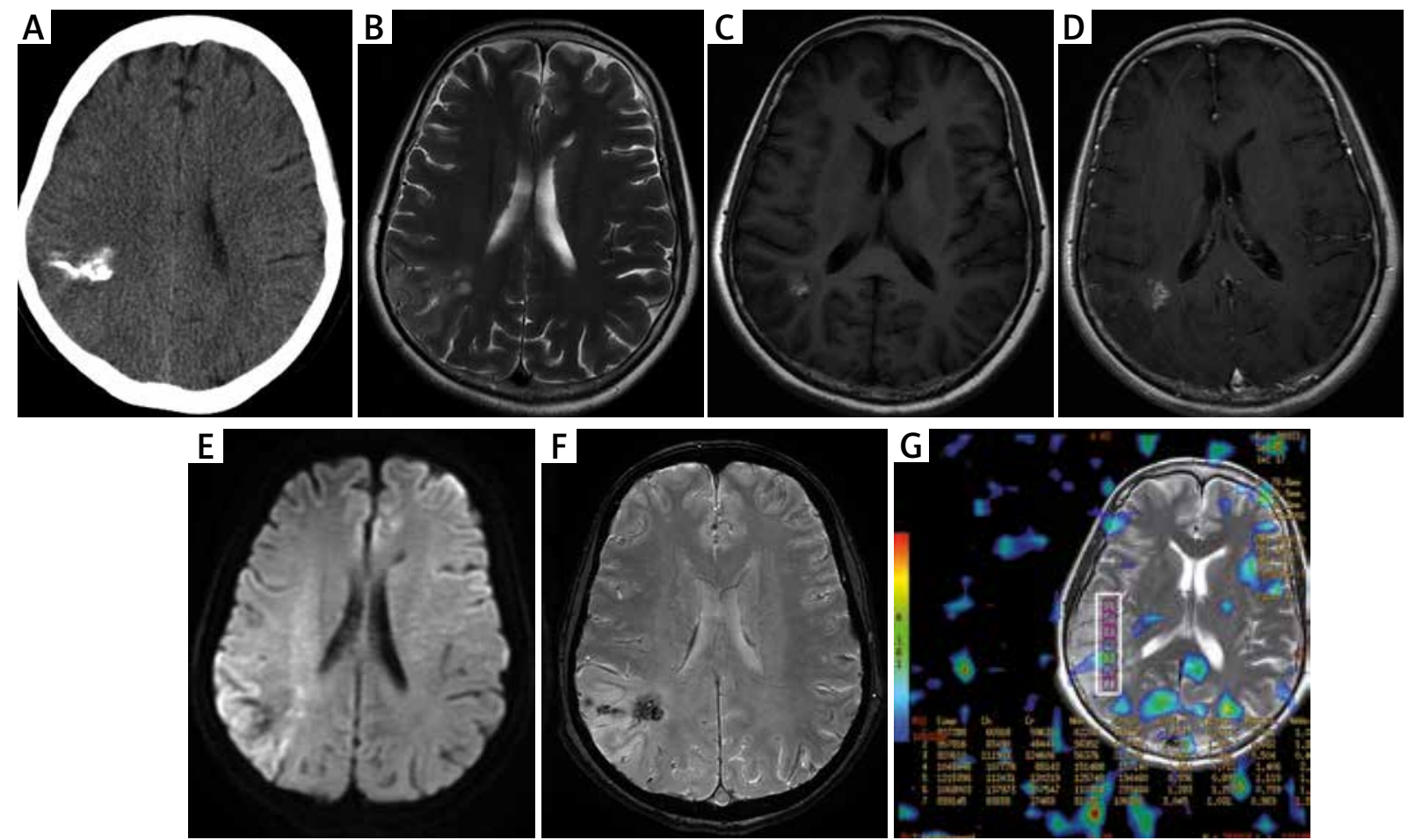

Fig. 1. Preoperative CT and MRI imaging of the lesion. A) Axial CT scans show a massively calcified lesion in the right parietal lobe. B-D) MRI shows an ill-defined and irregular mass with high-low mixed signals on both T2- and T1-weighted images and a slight contrast on enhanced images. E) Diffusion-weighted images (DWI) show heterogeneous signal intensity in the lesion region. F) T2 star-weighted angiography (SWAN) show hypointensity of the lesion with some curved shape-like signals. G) Neither abnormally elevated Cho nor abnormally reduced NAA is detected by magnetic resonance spectroscopy (MRS). 

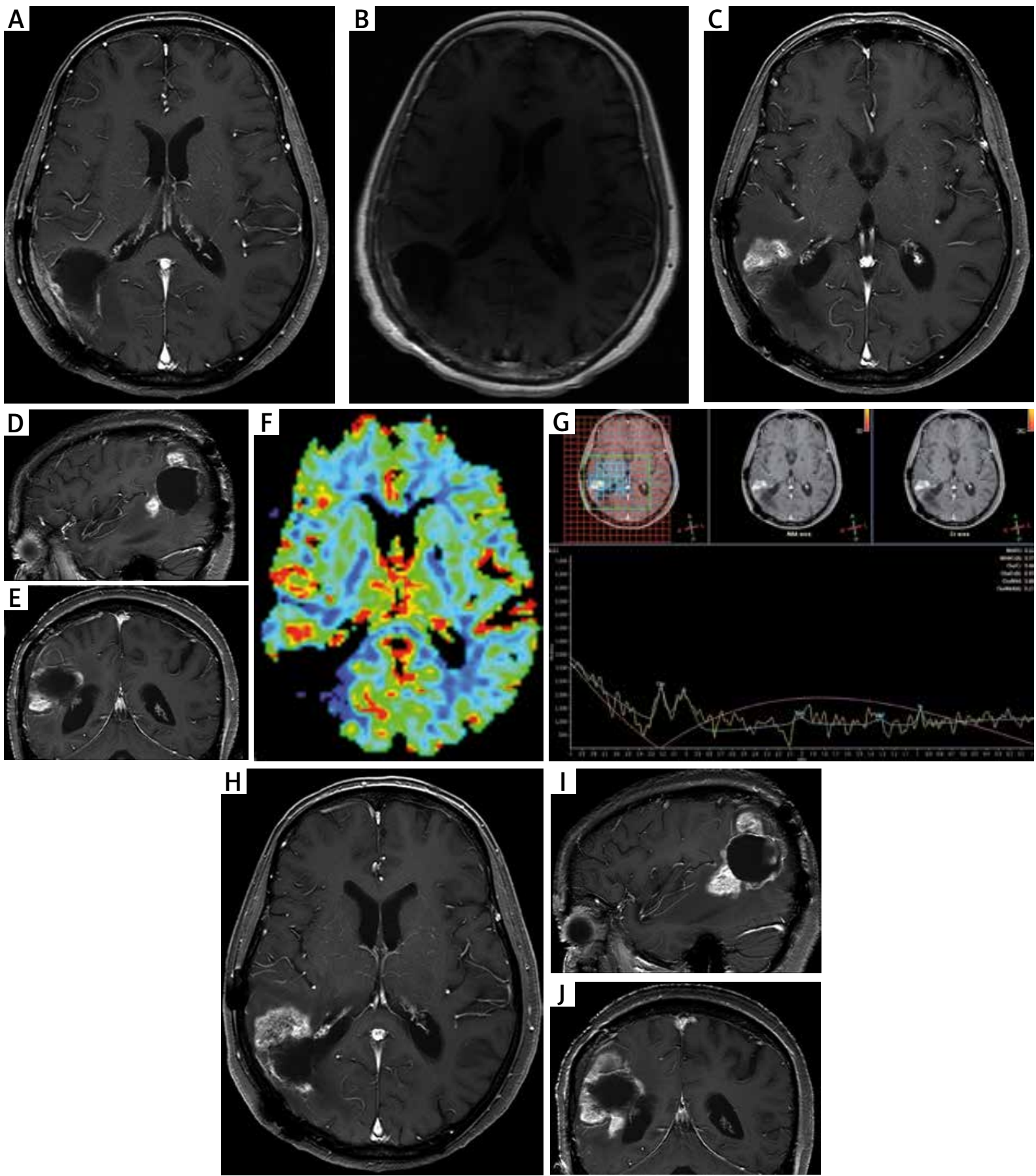

Fig. 2. Postoperative MRI and imaging follow-up of the lesion. A) Postoperative MRI reveals total resection of the lesion. B) MRI at the 3-month postoperative follow-up demonstrates no evidence of tumour relapse. C-E) MRI at 8 months after the operation show enhanced lesions around the residual cavity. F) MR perfusion-weighted imaging (PWI) reveal high perfusion of the new lesion located infra-anterior to the cavity. G) Spectroscopy imaging (MRS) reveal the elevated Cho signal and increased Cho/NAA ratio of the region of interest within the new lesions. $\mathrm{H}-\mathrm{J}$ ) MRI at the one-year follow-up reveals a bigger size of the new lesions than that shown in the last examination. 

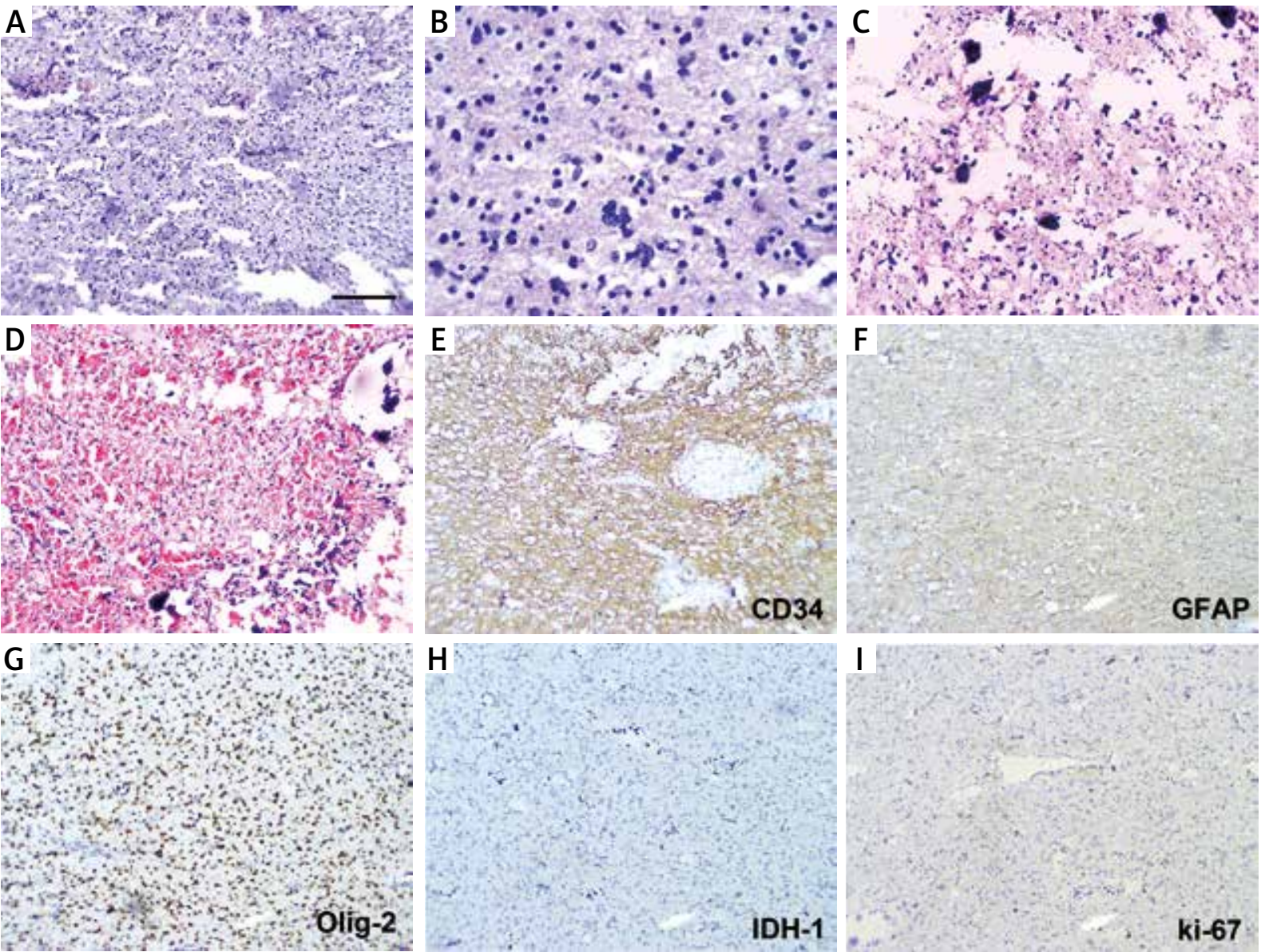

Fig. 3. Micrographic findings of the lesion. A, B) Micrography reveals a moderately cellular tumour composed of oval or round cells with small nuclei (A, 10x; B, 40x). C, D) Extensive deposits of calcium and diffuse microhaemorrhage in the tumour mass are observed (10x). E) Immunohistochemical staining demonstrates strong positivity of CD34 in neoplastic cells (10x). F, G) The tumour cells are uncertainly stained for GFAP but intensively stained for Olig-2 (10x). H) Mutant IDH1 staining is negative in this tumour. I) Staining of ki-67 indicates proliferation index as 1\% (10x).

Pathological examinations showed a glial tumour composed of oval or round cells with small nuclei and ample cytoplasm (Fig. 3A, B). Mitosis, nuclear atypia, necrosis, vascular proliferation, eosinophilic granular bodies, and Rosenthal fibres were all absent in the predominant tumour cells. Extensive calcification was identified in the main tumour mass and diffuse microhaemorrhage was observed in some places (Fig. 3C, D). Remarkably, immunohistochemistry revealed an intensive and diffuse positivity for CD34 within neoplastic cells (Fig. 3E). There were also immunopositivity for NSE, epidermal growth factor receptor (EGFR), ATRX, and glial marker Olig-2 but uncertain positivity of glial fibrillary acidic protein (GFAP) staining on the tumour cells (Fig. 3F, G). And the tumour cells also showed focally positive for $\mathrm{VIM}$, but negative immunostaining for P53, Topoll, CyD1, EMA, and IDH1 (Fig. 3H). The ki-67 labelling index was 1\% (Fig. 3I). The FISH analysis showed the wild-type status of chromosome $1 \mathrm{q}$ and $19 q$. Sequence analysis demonstrated no mutation in IDH1, IDH2, ATRX, TP53, H3F3A, HIST1H3B, BRAF V600E, EGFR, PIK3CA, PTEN, but c.1-146C >T in TERT promoter. Other gene mutations detected by the targeted sequencing was shown in Table I. An extremely low rate $(3.94 \%)$ of MGMT promoter methylation was found by bisulfite sequencing. The copy number of EGFR was 2.91 without amplification, and chromosome 7 gain but no chromosome 10 loss was found. The status of microsatellite of this tumour was stable and its tumour mutation burden was 3.0/MB. 
Table I. List of all mutated genes detected in this case

\begin{tabular}{|c|c|c|c|c|c|}
\hline Gene name & Changes of nucleotides & $\begin{array}{c}\text { Mutation } \\
\text { frequency }(\%)\end{array}$ & Gene name & Changes of nucleotides & $\begin{array}{c}\text { Mutation } \\
\text { frequency (\%) }\end{array}$ \\
\hline$A B C D 1$ & c. $1823 G>A$ & 5.13 & LRRIQ3 & c. $1450 \mathrm{C}>\mathrm{T}$ & 14.89 \\
\hline$A B C D 1$ & C. $1816 T>C$ & 5.00 & MAP1A & c. $6190 \mathrm{~A}>\mathrm{C}$ & 15.24 \\
\hline ACAN & c. $4281 T>G$ & 10.15 & MAP2 & c. $633 \mathrm{~T}>\mathrm{G}$ & 7.36 \\
\hline$A G R N$ & c.5399G >A & 10.71 & MDN1 & C.9869A >C & 13.78 \\
\hline AKTIP & C.318G>C & 8.89 & MID2 & c.600T>G & 15.65 \\
\hline$A L P P$ & c.37_39delTGC & 9.09 & MINOS1-NBL1 & c.148G >A & 9.02 \\
\hline$A N K R D 30 B P 2$ & n.3005+1G>T & 5.00 & MTRR & c. $1430 C>G$ & 10.23 \\
\hline ASCC 3 & c. $4351 \mathrm{~A}>\mathrm{C}$ & 16.11 & NF1 & c.305T>G & 13.83 \\
\hline C9orf3 & c. $1437 \mathrm{~T}>\mathrm{G}$ & 11.62 & NPC1 & c.3038T >G & 15.96 \\
\hline CACNA1I & c. $843 \mathrm{~T}>\mathrm{G}$ & 11.04 & NPIPB 15 & C. $578 \mathrm{G}>\mathrm{A}$ & 9.86 \\
\hline CAMKV & c. $308 C>T$ & 8.38 & OR10G2 & c.600T>G & 10.33 \\
\hline CASC3 & c. $1035 T>G$ & 12.05 & OR4S1 & c. $510 T>G$ & 14.11 \\
\hline$C C D C 14$ & c. $640 G>C$ & 7.03 & OR7E24 & C. $989 A>C$ & 12.42 \\
\hline CCDC168 & c.14664A>G & 7.25 & PDE1A & c. $237 \mathrm{~T}>\mathrm{G}$ & 15.91 \\
\hline CCL14 & c. $79+1 G>A$ & 11.50 & PDLIM7 & c.898G >A & 18.75 \\
\hline CHRNA3 & C. $1258 A>C$ & 13.98 & PHF24 & c.390T>G & 18.68 \\
\hline CHRNG & c. $528 \mathrm{~T}>\mathrm{G}$ & 10.00 & PLEKHO1 & C. $126 \mathrm{~A}>\mathrm{C}$ & 6.90 \\
\hline CIDEA & C. $40 C>T$ & 7.69 & PLEKHO1 & C. $125 \mathrm{~A}>\mathrm{C}$ & 7.02 \\
\hline CNN2 & C. $965 C>A$ & 5.56 & PLEKHO1 & C. $127 A>C$ & 6.87 \\
\hline COL22A1 & C. $1219 C>T$ & 14.12 & PRDM12 & c.570+16_570+17del & 6.56 \\
\hline CORO1C & C.1366A>C & 11.69 & $P R R C 2 C$ & c. $800 T>G$ & 6.80 \\
\hline CPNE1 & C. $685 A>C$ & 13.01 & PRUNE2 & c.7239delA & 10.40 \\
\hline DCAF11 & C.889A>C & 12.12 & PTPRK & c. $2686 A>C$ & 10.02 \\
\hline DCAF11 & $\mathrm{C} .887 \mathrm{~A}>\mathrm{C}$ & 12.12 & PTPRZ1 & c.2043_2076dupACGTGTTGATG & 8.26 \\
\hline$D D O$ & c. $1048 G>A$ & 5.63 & & AATCTGAGAAGACAACCAAGTCC & \\
\hline$D D X 11$ & c.664C $>T$ & 5.08 & QKI & c.150_152delAGC & 11.54 \\
\hline DMTF1 & C. $88 \mathrm{~A}>\mathrm{C}$ & 9.63 & RELN & C.1402A>C & 9.09 \\
\hline DNAH6 & c. $10702 C>T$ & 23.08 & RPTN & c. $1811 C>A$ & 8.20 \\
\hline $\begin{array}{l}\text { DNAJC16 } \\
\text { DNHD1 }\end{array}$ & $\begin{array}{l}\text { C.1199A>C } \\
\text { C.6535A>C }\end{array}$ & $\begin{array}{l}19.80 \\
11.64\end{array}$ & RTKN2 & c. $175 \mathrm{~A}>\mathrm{C}$ & 19.17 \\
\hline ELF3 & c.15T>G & 21.37 & SASH1 & c. $1732 \mathrm{~A}>\mathrm{C}$ & 17.83 \\
\hline EML6 & c.909T>G & 12.32 & SEMA6D & c. $1253+2 T>G$ & 11.44 \\
\hline ERN1 & C. $1057 A>C$ & 12.50 & SIPA1L1 & c. $742 A>C$ & 5.97 \\
\hline FAHD2A & $\mathrm{c} .80 \mathrm{~T}>\mathrm{G}$ & 6.76 & SLC25A3 & c. $34 \mathrm{~A}>\mathrm{C}$ & 9.86 \\
\hline $\begin{array}{l}\text { FAM155A } \\
\text { FAR2 }\end{array}$ & $\frac{c .256 \_258 d e l C A G}{c .853 A>C}$ & $\begin{array}{l}10.81 \\
13.78\end{array}$ & SLC44A1 & c. $625 A>G$ & 8.55 \\
\hline FAT4 & c.3983T>G & 13.92 & STIM 1 & c. $1013 A>C$ & 12.39 \\
\hline FBN2 & c.737C $>T$ & 10.13 & STX3 & $c .86 C>T$ & 5.25 \\
\hline FBXL13 & c.655G >C & 38.00 & TCF20 & c.1292A>C & 12.08 \\
\hline FCAMR & C. $1208 \mathrm{~A}>\mathrm{C}$ & 19.59 & TECTA & $\mathrm{c} .870 \mathrm{~T}>\mathrm{G}$ & 7.95 \\
\hline $\begin{array}{l}\text { GPR50 } \\
\text { GRIA1 }\end{array}$ & $\begin{array}{c}\text { c.914A }>T \\
\text { c.1641T>C }\end{array}$ & $\begin{array}{c}9.23 \\
14.53\end{array}$ & TERF2IP & c.910_912delGAA & 6.52 \\
\hline GRIA4 & c. $1635 T>G$ & 15.63 & TERT & c.1-146C $>T$ & 14.18 \\
\hline GUCY2F & c. $3167 A>T$ & 17.05 & TFAP2D & c.1306C>T & 14.89 \\
\hline HEXDC & $c .26 \mathrm{~T}>\mathrm{G}$ & 19.70 & THBS1 & c.3003T>G & 14.63 \\
\hline HSPA4 & $\mathrm{c} .84 \mathrm{~T}>\mathrm{G}$ & 11.37 & TMEM39A & c.179G $>A$ & 6.12 \\
\hline$\frac{\text { IGHV5-51 }}{\text { IKZF3 }}$ & $\begin{array}{l}c .331 G>A \\
C .104 A>C\end{array}$ & $\begin{array}{l}11.56 \\
17.36\end{array}$ & TNC & c.3907A>C & 14.36 \\
\hline IIPOS & C. $1008 \mathrm{~T}>\mathrm{G}$ & $\begin{array}{l}1 / .30 \\
19.27\end{array}$ & TPST2 & c. $964 A>C$ & 14.21 \\
\hline ITPR3 & C.1996A>C & 8.74 & TTN & c.7229A>C & 8.82 \\
\hline KMT2D & c.10774A>C & 21.56 & TTN & c. $27601 A>C$ & 8.49 \\
\hline LILRA1 & c. $1387 A>C$ & 11.21 & WDR6 & c.3020A>C & 8.38 \\
\hline LOC101060017 & $c .145 C>T$ & 6.82 & $X I R P 1$ & c.5294T>G & 13.11 \\
\hline LOC440243 & C. $1691 \mathrm{~A}>C$ & 5.31 & ZNF260 & c.790A $>C$ & 9.73 \\
\hline LRP4 & c. $4188 T>G$ & 6.44 & ZNF343 & c.1900A>C & 19.77 \\
\hline
\end{tabular}


Subsequently, the patient received the Stupp protocol containing concomitant temozolomide (TMZ) and radiotherapy followed by 6 cycles of TMZ, which was developed by our multidisciplinary team including neurosurgeons, neurooncologists, pathologists, radiologists, and radiotherapists. Enhanced MRI examination at the 3-month postoperative followup demonstrated no evidence of tumour relapse (Fig. 2B). However, 5 months later, the patient presented with a slight headache and received an MRI scan, which showed several enhanced nodules around the residual cavity (Fig. 2C-E). Then, MR perfusion-weighted imaging (PWI) and spectroscopy imaging (MRS) were suggested to help differentiate pseudoprogression from glioma progression. High perfusion and increased Cho/NAA ratio of the region of interest indicated tumour progression (Fig. 2F, G). But the patient and her family refused reoperation, and the recurrent lesion grew rapidly at the one-year follow-up (Fig. 2H-J).

\section{Discussion}

A lot of evidence has demonstrated that IDHWT gliomas have distinct character compared to IDH-mutant tumours. Importantly, the status of IDH, combined with $1 p / 19 q$ co-deletions, reclassifies the whole entity of histological low-grade gliomas within the 2016 WHO classification. Moreover, the group of IDH-WT histological low-grade gliomas probably still includes a variety of subclasses with distinct morphological appearances, molecular pathogenesis and clinical outcomes. Further stratification by genetic analyses is warranted to resolve the majority of cases into other tumour entities.

Pre-GBM is a newly-established but rare group involving IDH-WT diffuse astrocytoma, featured by a specific set of molecular markers containing high-level EGFR amplification, combination of whole chromosome 7 gain and whole chromosome 10 loss $(+7 /-10)$ or TERT promoter mutation, as recommended by the Consortium to Inform Molecular and Practical Approaches to CNS Tumor Taxonomy (cIMPACT-NOW) [4]. Even though there are no histopathological signs of high-grade nature in these tumours, they show genetic and/or epigenetic profiles characteristic of GBM, behave most aggressively resembling GBM, and have a similar clinical course. Current findings reveal that this type of glioma may represent an early stage of GBM and rapidly progress into histologically grade IV tumour. Though our case met the diagnosis criteria of molecular features, the morphological features and uncertainly positive GFAP expression, combined with the aberrant and extensive expression of CD34 on tumour cells, complicated the diagnosis of the tumour in our study as a diffuse astrocytoma.

CD34 is identified as a marker of hematopoietic progenitor cells and is also expressed by vascular endothelial cells. In the normal brain, this protein appears transiently in the central nervous system during early neurulation and cannot be detected in mature neuroectodermal progenies [7]. But CD34 expression has been demonstrated in neuroepithelial neoplasia, particularly in some types of low-grade glioma with distinct features. As reported, CD34 immunoactivity had been observed in pleomorphic xanthoastrocytomas (PXA) and ganglioglioma with high frequency (present in $50-80 \%$ of both groups) and was often seen recorded in pilocytic astrocytoma (PA) $[6,7]$. However, PXA is characterized by cellular pleomorphism with spindle cells, large pleomorphic and frequently multinucleated cells, granular bodies, and positive reticulin staining $[10,18]$. Likewise, PA possesses the characteristic of eosinophilic granular bodies as well as Rosenthal fibres and a biphasic microcystic pattern, and ganglioglioma is a combination of neuronal and glial cell elements and also harbours Rosenthal fibres and eosinophilic granular bodies in many cases. Moreover, BRAF V600E mutations occur in a significant proportion of these types of tumours and are associated with CD34 expression [6,10,11]. Another type of low-grade neuroepithelial tumours called polymorphous lowgrade neuroepithelial tumour of the young (PLNTY) exhibits intense labelling for CD34, but PLNTY also shows histopathological variability with frequently prominent oligodendroglioma-like components and specific DNA methylation signature and genetic alterations [3,13]. These underline the importance of morphological examinations combined with molecular analysis in the differential diagnosis of gliomas with unusual histopathological features and indicate an entirely different entity involving our case lacking these morphological and molecular characteristics. This entity may also comprise another paediatric case of low-grade glioma with extensive expression of CD34 [15]. Furthermore, diffuse CD34 expression in such novel gliomas with aggressive behaviours may reflect the inherent nature of tumour develop- 
ment. A more recent study found that glioma stem cells with differentiation into endothelial cells could form new blood vessels and these glioma-derived endothelial cells were immunoreactive for CD34 and GFAP [14]. These CD34-expressing glioma cells may play an important role in neovascularization to promote the tumor to grow aggressively.

TERT mutations have been investigated deeply into glioma classification and prognosis. Hotspot mutations in the TERT promoter leads to increased telomerase activity for maintaining tumour malignant phenotypes. TERT promoter mutations occur frequently in primary GBM and almost all IDH-mutant, 1p/19q-codeleted oligodendroglioma [12], while they are less likely to appear in diffuse astrocytoma [1] and are occasionally found in some types of IDHWT glial neoplasms without WHO grade IV histology or aggressive behaviour (for example, PXA, ganglioglioma, anaplastic glioma with piloid features, and ependymoma) [19]. Moreover, previous observations implicate an inverse association of TERT promoter and IDH mutations in GBM, conversely, IDH mutant group accounts for a large proportion of diffuse astrocytoma with TERT promoter mutations [8,9]. These findings indicate different roles of TERT in glioma initiation. The status of TERT promoter has also been found as a strong prognosticator not only in GBM, but also in diffuse gliomas with non-GBM histology. As demonstrated, IDH-mutant/TERT-mutated GBM showed the most favourable prognosis followed by the IDHmutant/TERT-WT group, and IDH-WT/TERT-mutant tumours displayed a significantly shorter survival time than any other group [2]. In WHO grade II and grade III IDH-WT gliomas, the presence of the TERT promoter mutation was also associated with poor prognosis [17]. Further integrated analysis implied that the survival of IDH-WT diffuse lower-grade gliomas with only TERT promoter mutation well matched the survival of the IDH-WT GBMs [16]. These findings support the clinical and biological similarity between the two histological types of gliomas.

Either way, the case in our study showing histological features of low-grade tumours, wild type status of IDH, extensive CD34 expression, and TERT promoter mutation is a rapidly progressing malignant tumour and should be taken into account as a member of the pre-GBM group. Herein, we exhibited specific imaging characteristics and pathologic findings of one tumour, but more detailed informa- tion about this entity requires future investigations on a large scale.

\section{Acknowledgements}

This work was supported by the National Natural Science Foundation of China (No. 81902538) and Shanghai Sailing Program (19YF1448200).

\section{Disclosure}

The authors report no conflict of interest.

\section{References}

1. Arita H, Narita Y, Fukushima S, Tateishi K, Matsushita Y, YoshidaA, Miyakita Y, Ohno M, Collins VP, Kawahara N, Shibui S, Ichimura K. Upregulating mutations in the TERT promoter commonly occur in adult malignant gliomas and are strongly associated with total 1p19q loss. Acta Neuropathol 2013; 126: 267-276.

2. Arita H, Yamasaki K, Matsushita Y, Nakamura T, Shimokawa A, Takami H, Tanaka S, Mukasa A, Shirahata M, Shimizu S, Suzuki K, Saito K, Kobayashi K, Higuchi F, Uzuka T, Otani R, Tamura K, Sumita K, Ohno M, Miyakita Y, Kagawa N, Hashimoto N, Hatae R, Yoshimoto K, Shinojima N, Nakamura H, Kanemura Y, Okita Y, Kinoshita M, Ishibashi K, Shofuda T, Kodama Y, Mori K, Tomogane Y, Fukai J, Fujita K, Terakawa Y, Tsuyuguchi N, Moriuchi S, Nonaka M, Suzuki H, Shibuya M, Maehara T, Saito N, Nagane M, Kawahara N, Ueki K, Yoshimine T, Miyaoka E, Nishikawa R, Komori T, Narita Y, Ichimura K. A combination of TERT promoter mutation and MGMT methylation status predicts clinically relevant subgroups of newly diagnosed glioblastomas. Acta Neuropathol Commun 2016; 4: 79

3. Bitar M, Danish SF, Rosenblum MK. A newly diagnosed case of polymorphous low-grade neuroepithelial tumor of the young. Clin Neuropathol 2018; 37: 178-181.

4. Brat DJ, Aldape K, Colman H, Holland EC, Louis DN, Jenkins RB, Kleinschmidt-DeMasters BK, Perry A, Reifenberger G, Stupp R, von Deimling A, Weller M: cIMPACT-NOW update 3: recommended diagnostic criteria for "Diffuse astrocytic glioma, IDH-wildtype, with molecular features of glioblastoma, WHO grade IV”. Acta Neuropathol 2018; 136: 805-810.

5. Cancer Genome Atlas Research Network, Brat DJ, Verhaak RG, Aldape KD, Yung WK, Salama SR, Cooper LA, Rheinbay E, Miller CR, Vitucci M, Morozova O, Robertson AG, Noushmehr $H$, Laird PW, Cherniack AD, Akbani R, Huse JT, Ciriello G, Poisson LM, Barnholtz-Sloan JS, Berger MS, Brennan C, Colen RR, Colman H, Flanders AE, Giannini C, Grifford M, lavarone A, Jain R, Joseph I, Kim J, Kasaian K, Mikkelsen T, Murray BA, O’Neill BP, Pachter L, Parsons DW, Sougnez C, Sulman EP, Vandenberg SR, Van Meir EG, von Deimling A, Zhang H, Crain D, Lau K, Mallery D, Morris S, Paulauskis J, Penny R, Shelton T, Sherman M, Yena P, Black A, Bowen J, Dicostanzo K, Gastier-Foster J, Leraas KM, Lichtenberg TM, Pierson CR, Ramirez NC, Taylor C, Weaver S, Wise L, Zmuda E, Davidsen T, Demchok JA, Eley G, Ferguson ML, Hutter CM, Mills Shaw KR, Ozenberger BA, Sheth M, Sofia HJ, Tarnuzzer R, Wang Z, Yang L, Zenklusen JC, Ayala B, Baboud J, Chudamani S, 
Jensen MA, Liu J, Pihl T, Raman R, Wan Y, Wu Y, Ally A, Auman JT, Balasundaram M, Balu S, Baylin SB, Beroukhim R, Bootwalla MS, Bowlby R, Bristow CA, Brooks D, Butterfield Y, Carlsen R, Carter S, Chin L, Chu A, Chuah E, Cibulskis K, Clarke A, Coetzee SG, Dhalla N, Fennell T, Fisher S, Gabriel S, Getz G, Gibbs R, Guin R, Hadjipanayis A, Hayes DN, Hinoue T, Hoadley K, Holt RA, Hoyle AP, Jefferys SR, Jones S, Jones CD, Kucherlapati R, Lai PH, Lander E, Lee S, Lichtenstein L, Ma Y, Maglinte DT, Mahadeshwar HS, Marra MA, Mayo M, Meng S, Meyerson ML, Mieczkowski PA, Moore RA, Mose LE, Mungall AJ, Pantazi A, Parfenov M, Park PJ, Parker JS, Perou CM, Protopopov A, Ren X, Roach J, Sabedot TS, Schein J, Schumacher SE, Seidman JG, Seth S, Shen H, Simons JV, Sipahimalani P, Soloway MG, Song X, Sun H, Tabak B, Tam A, Tan D, Tang J, Thiessen N, Triche T, Jr., Van Den Berg DJ, Veluvolu U, Waring S, Weisenberger DJ, Wilkerson MD, Wong T, Wu J, Xi L, Xu AW, Yang L, Zack TI, Zhang J, Aksoy BA, Arachchi H, Benz C, Bernard B, Carlin D, Cho J, DiCara D, Frazer S, Fuller GN, Gao J, Gehlenborg N, Haussler D, Heiman DI, lype L, Jacobsen A, Ju Z, Katzman S, Kim H, Knijnenburg T, Kreisberg RB, Lawrence MS, Lee W, Leinonen K, Lin P, Ling S, Liu W, Liu Y, Liu Y, Lu Y, Mills G, Ng S, Noble MS, Paull E, Rao A, Reynolds S, Saksena G, Sanborn Z, Sander C, Schultz N, Senbabaoglu Y, Shen R, Shmulevich I, Sinha R, Stuart J, Sumer SO, Sun Y, Tasman N, Taylor BS, Voet D, Weinhold N, Weinstein JN, Yang D, Yoshihara K, Zheng S, Zhang W, Zou L, Abel T, Sadeghi S, Cohen ML, Eschbacher J, Hattab EM, Raghunathan A, Schniederjan MJ, Aziz D, Barnett G, Barrett W, Bigner DD, Boice L, Brewer C, Calatozzolo C, Campos B, Carlotti CG, Jr., Chan TA, Cuppini L, Curley E, Cuzzubbo S, Devine K, DiMeco F, Duell R, Elder JB, Fehrenbach A, Finocchiaro G, Friedman W, Fulop J, Gardner J, Hermes B, Herold-Mende C, Jungk C, Kendler A, Lehman NL, Lipp E, Liu O, Mandt R, McGraw M, McLendon R, McPherson C, Neder L, Nguyen P, Noss A, Nunziata R, Ostrom QT, Palmer C, Perin A, Pollo B, Potapov A, Potapova O, Rathmell WK, Rotin D, Scarpace L, Schilero C, Senecal K, Shimmel K, Shurkhay V, Sifri S, Singh R, Sloan AE, Smolenski K, Staugaitis SM, Steele R, Thorne L, Tirapelli DP, Unterberg A, Vallurupalli M, Wang Y, Warnick R, Williams F, Wolinsky Y, Bell S, Rosenberg M, Stewart C, Huang F, Grimsby IL, Radenbaugh AJ, Zhang J. Comprehensive, integrative genomic analysis of diffuse lower-grade gliomas. N Engl J Med 2015; 372: 2481-2498.

6. Chappe C, Padovani L, Scavarda D, Forest F, Nanni-Metellus I, Loundou A, Mercurio S, Fina F, Lena G, Colin C, Figarella-Branger D. Dysembryoplastic neuroepithelial tumors share with pleomorphic xanthoastrocytomas and gangliogliomas BRAF(V600E) mutation and expression. Brain Pathol 2013; 23: 574-583.

7. Giulioni M, Marucci G, Cossu M, Tassi L, Bramerio M, Barba C, Buccoliero AM, Vornetti G, Zenesini C, Consales A, De Palma L, Villani F, Di Gennaro G, Vatti G, Zamponi N, Colicchio G, Marras CE. CD34 expression in low-grade epilepsy-associated tumors: relationships with clinicopathologic features. World Neurosurg 2019; 121: e761-e768.

8. Hewer E, Prebil N, Berezowska S, Gutt-Will M, Schucht P, Dettmer MS, Vassella E. Diagnostic implications of TERT promoter mutation status in diffuse gliomas in a routine clinical setting. Virchows Archiv 2017; 471: 641-649.

9. Koelsche C, Sahm F, Capper D, Reuss D, Sturm D, Jones DT, Kool M, Northcott PA, Wiestler B, Bohmer K, Meyer J, Mawrin C, Hartmann C, Mittelbronn M, Platten M, Brokinkel B, Seiz M, Her-
old-Mende C, Unterberg A, Schittenhelm J, Weller M, Pfister S, Wick W, Korshunov A, von Deimling A. Distribution of TERT promoter mutations in pediatric and adult tumors of the nervous system. Acta Neuropathol 2013; 126: 907-915.

10. Koelsche C, Sahm F, Wohrer A, Jeibmann A, Schittenhelm J, Kohlhof P, Preusser M, Romeike B, Dohmen-Scheufler H, Hartmann C, Mittelbronn M, Becker A, von Deimling A, Capper D. BRAF-mutated pleomorphic xanthoastrocytoma is associated with temporal location, reticulin fiber deposition and CD34 expression. Brain Pathol 2014; 24: 221-229.

11. Kowalewski A, Durslewicz J, Zdrenka M, Grzanka D, Szylberg L. Clinical relevance of BRAF V600E mutation status in brain tumors with a focus on a novel management algorithm. Target Oncol 2020; 15: 531-540.

12. Kristensen BW, Priesterbach-Ackley LP, Petersen JK, Wesseling P. Molecular pathology of tumors of the central nervous system. Ann Oncol 2019; 30: 1265-1278.

13. Lelotte J, Duprez T, Raftopoulos C, Michotte A. Polymorphous low-grade neuroepithelial tumor of the young: case report of a newly described histopathological entity. Acta Neurol Belg 2020; 120: 729-732.

14. Mei X, Chen YS, Chen FR, Xi SY, Chen ZP. Glioblastoma stem cell differentiation into endothelial cells evidenced through live-cell imaging. Neuro Oncol 2017; 19: 1109-1118.

15. Nagaishi M, Yokoo H, Nobusawa S, Fujii Y, Sugiura Y, Suzuki R, Tanaka Y, Suzuki K, Hyodo A. A distinctive pediatric case of lowgrade glioma with extensive expression of CD34. Brain Tumor Pathol 2016; 33: 71-74.

16. Tesileanu CMS, Dirven L, Wijnenga MMJ, Koekkoek JAF, Vincent A, Dubbink HJ, Atmodimedjo PN, Kros JM, van Duinen SG, Smits M, Taphoorn MJB, French PJ, van den Bent MJ. Survival of diffuse astrocytic glioma, IDH1/2 wildtype, with molecular features of glioblastoma, WHO grade IV: a confirmation of the CIMPACT-NOW criteria. Neuro Oncol 2020; 22: 515-523.

17. Vuong HG, Tran TTK, Ngo HTT, Pham TQ, Nakazawa T, Fung KM, Hassell L, Katoh R, Kondo T. Prognostic significance of genetic biomarkers in isocitrate dehydrogenase-wild-type lowergrade glioma: the need to further stratify this tumor entity a meta-analysis. Eur J Neurol 2019; 26: 379-387.

18. Watanabe N, Ishikawa E, Kohzuki H, Sakamoto N, Zaboronok A, Matsuda M, Shibuya M, Matsumura A. Malignant transformation of pleomorphic xanthoastrocytoma and differential diagnosis: case report. BMC Neurol 2020; 20: 21.

19. Yeaney GA, Brat DJ. What every neuropathologist needs to know: update on cIMPACT-NOW. J Neuropathol Exp Neurol 2019; 78: 294-296. 